\title{
O Uso Pedagógico do Smartphone na Sala de Aula: Um Relato de Experiência na Formação de Professores
}

\author{
Elvis Medeiros de Melo, Juliana Lacerda de Oliveira, Nathalie Rose Ramos da \\ Fonseca Araújo
}

Instituto Metrópole Digital - Universidade Federal do Rio Grande do Norte (UFRN) Av. Sen. Salgado Filho, 3000 - Lagoa Nova, CEP: 59.078-970 - Natal - RN - Brasil

\{elvismedeiros.mm, julacerda01, nathalieroses\}@gmail.com

\begin{abstract}
The popularization of mobile devices has promoted changes in society reaching the classroom. The use of the smartphone as a possibility for the expansion of learning appears shyly in the Brazilian context, also caused by the lack of training. Given this scenario comes the perspective of a workshop to help in the training of teachers regarding the pedagogical possibilities that this tool can offer. Among the results, three classes were planned using the smartphone, with $80 \%$ considering as negative the lack of WiFi in schools, making it impossible to use. In addition, $89 \%$ recognize the smartphone as a tool that promotes engagement and interaction.

Resumo. A popularização dos dispositivos móveis promoveu mudanças na sociedade chegando a sala de aula. $O$ uso do smartphone como possibilidade para a ampliação da aprendizagem aparece timidamente no contexto brasileiro, ocasionado também pela falta de formação. Diante desse cenário surge a perspectiva de uma oficina para ajudar na formação dos professores quanto às possibilidades pedagógicas que essa ferramenta pode oferecer. Dentre os resultados, foram planejadas três aulas com o uso do smartphone, com $80 \%$ considerando como ponto negativo a falta de WiFi nas escolas, impossibilitando seu uso. Além disso, $89 \%$ reconhecem o smartphone como ferramenta que promove engajamento e interação.
\end{abstract}

\section{Introdução}

Com o barateamento dos smartphones e a popularização da internet, esses dispositivos móveis ganharam cada vez mais espaço em nosso cotidiano e nas atividades executadas sejam no âmbito profissional, acadêmico ou mesmo de entretenimento. Com os smartphones hoje nós podemos, além de telefonar, enviar mensagens, registrar e consultar a agenda, tirar e ver fotos, gravar vídeos, assistir filmes e programas de TV, jogar, escolher e seguir melhores rotas no trânsito e por aí vai. O fato é que as tecnologias móveis estão influenciando nossas formas de perceber e interagir com o mundo a nossa volta [Sharples et al. 2009]. Essas mudanças chegam na sala de aula e os professores não sabem como proceder com o seu uso. Por não saber, acabam por proibí-los.

O smartphone não deve ser colocado como um inimigo do professor, mas sim como uma tecnologia que pode ser usada como um auxiliar didático nas aulas quando devidamente explorado. Ele pode dar todas as respostas que os alunos buscam, mas só o uso pedagógico dessa ferramenta consegue provocar a construção do conhecimento pelo aluno. Claro que não basta sair usando o dispositivo sem planejamento. É preciso 
VIII Congresso Brasileiro de Informática na Educação (CBIE 2019)

Anais dos Workshops do VIII Congresso Brasileiro de Informática na Educação (WCBIE 2019)

explorar o que de diferente essa tecnologia pode oportunizar aos alunos comparada a tecnologias mais comuns na escola como lápis, papel, ou qualquer outro tipo de de material. Para tanto, a Unesco (2014) sugere que haja formações em larga escala para treinamento de professores para o uso dessas tecnologias em suas aulas de maneira pedagógica.

O objetivo deste trabalho foi, com o intuito de formar professores para o uso pedagógico dos smartphones, fazer um relato de experiência sobre uma formação aplicada com 30 profissionais da área de tecnologia educacional para o uso pedagógico dos smartphones no âmbito de um congresso sobre tecnologias na educação.

O artigo está dividido em 6 seções, além desta introdução, uma seção na qual tratamos sobre o uso pedagógico do smartphone em sala de aula; uma seção na qual relatamos o processo metodológico da concepção; uma seção onde discorreremos sobre os resultados obtidos durante a formação, tais como o plano de aula desenvolvido pelos participantes e a avaliação final da formação; as considerações finais sobre a formação e referências usadas na constituição do texto.

\section{Tecnologia Móvel e Formação de Professores}

A partir de uma análise de políticas públicas de inserção de tecnologia nas escolas brasileiras, Borba e Lacerda (2015) promovem um debate sobre a utilização de smartphones nas salas de aula e argumentam em favor do que denominaram "Projeto Um Celular por Aluno". De acordo com os pesquisadores, tais dispositivos móveis já estão na escola pelas mãos dos alunos o que deve ser considerado, dentre outras vantagens, pela redução os custos de implementação como uma política pública. Não se pode negar que o fato de os alunos já possuírem o dispositivo é um elemento facilitador, é necessário que o poder público invista em infraestrutura mínima que subsidie as práticas. Para tanto, redes de internet e elétrica de qualidade são fundamentais, além do suporte pedagógico voltado à permanente formação docente para a devida apropriação didática que envolvam práticas com essas tecnologias.

As tecnologias móveis, sobretudo com a conectividade, possibilitam que a aprendizagem não esteja necessariamente restrita a um local físico no qual essas tecnologias estejam disponíveis, mas sim ao acesso às informações, à interação com outros usuários, à produção e ao compartilhamento de conteúdos [Silva e Silva 2014]. Isso significa que a aprendizagem, que passa a acontecer em qualquer lugar e em qualquer momento, cria outros contextos que permitem aos sujeitos novas formas de interagir e produzir conhecimentos. Para Santaella (2013), essa forma de aprender é ressignificada a partir do que é denominada de ubiquidade.

A formação de professores deve estar alinhada a essas realidades. Silva e Silva (2014) comentam que as tecnologias móveis conectadas podem redesenhar o contexto da escola com novas formas de comunicar, de informar, de gerenciar, de produzir conhecimentos, de ensinar e de aprender. Uma mudança de paradigma está posto como desafio para muitos professores e a mudança está vindo de fora para dentro, sendo que é papel da escola de preparar o aluno para a sociedade acaba se contrariando quando ela nega a inserção dessa tecnologia [Alves e Vieira 2015]. Os autores salientam que a forma na qual o professor integrará o smartphone em suas aulas dependerá de como esse uso é empreendido em suas atividades pessoais, sua postura frente ao seu uso na sala de aula e integração dessa tecnologia com determinados conteúdos escolares. 
Apesar disso, essas tecnologias são introduzidas nas escolas e os professores que enxergam essas potencialidades acabam que, por sua própria iniciativa (e com disponibilização do seu tempo pessoal) descobrem como funcionam, os seus possíveis benefícios e como as implementar na sala de aula [West 2013]. Como as escolas também não investem na formação na área da tecnologia [Campbell, Mehr e Mayer 2013], o resultado é habitualmente o insucesso anunciado. A formação dos professores é essencial à introdução com sucesso destes dispositivos.

Em relato de experiência sobre o uso pedagógico do smartphone no contexto escolar, Alves e Vieira (2015) observaram que tanto professores quanto alunos sabem que podem se apropriar dos smartphones durante as aulas, mas os docentes têm receio. Os autores salientam sobre a necessidade do desenvolvimento de um planejamento para uma aula desta forma. Além disso, relatam que é importante regularizar o uso do aparelho em sala de aula pela escola, com regras bem definidas.

Portanto, realizar uma formação para o uso pedagógico dos smartphones na qual serão abertos espaços para o debate sobre o uso dessa ferramenta, compartilhamento de experiências, uma prática com o uso da ferramenta, assim como uma avaliação do processo é um pontapé inicial para a provocação desses professores para o uso dessa ferramenta em suas aulas. Tendo isso em vista, abordaremos o procedimentos metodológicos para delineamento de uma formação para o uso pedagógico dessa ferramenta na próxima seção.

\section{Procedimentos Metodológicos}

Ao planejar uma formação para o uso pedagógico dos smartphones na sala de aula, pretendemos com que os participantes vivenciem uma prática pedagógica com o uso da ferramenta inserido em determinado contexto. Como objetivo geral da formação, com base nos trabalhos consultados, utilizamos o smartphone como um recurso pedagógico na sala de aula, fazendo com que o professor experimente uma prática dentro de um contexto. Delineamos como objetivos específicos: reconhecer o smartphone como uma possibilidade pedagógica; conhecer ferramentas online e offline para smartphones; e planejar uma aula com o uso do smartphone.

Os inscritos na oficina eram recepcionados e a cada um entregue uma pulseira de cores variadas. A provocação inicial foi a integração do smartphone na sala de aula, assim como temas relacionados às tecnologias móveis, tais como a aprendizagem móvel e a u-learning foram levantados. Para iniciarmos a oficina, utilizamos a ferramenta MentiMeter $^{l}$ e, assim, realizarmos um levantamento dos conhecimentos prévios dos participantes e realizar reflexão inicial sobre o uso do smartphone.

Demos continuidade apresentando o movimento BYOD (Bring Our Own Device), esse movimento apresenta o pensamento do uso do smartphone em sala de aula para ajudar na aprendizagem, na perspectiva um pra um [Borba e Lacerda 2014]. A luz desse movimento levantamos questões sobre a importância do planejamento da aula para o uso do celular e assim evitar a dispersão por parte dos alunos e dessa forma não alcançar o objetivo esperado.

\footnotetext{
${ }^{1}$ Disponível em: <mentimeter.com.br>. Acesso em: 29 set. 2019
} 
Em seguida, apresentamos o encurtador gg.gg e explicamos suas potencialidades e depois para o uso e aplicação do Plickers ${ }^{3}$, ferramenta que possibilita aplicar testes, realizar chamadas, praticar dinâmicas, entre outras possibilidades de uso. Além destas, apresentamos a ferramenta de edição de imagens e criação de vídeos do próprio google, o google fotos ${ }^{4}$. Na medida em que as ferramentas eram apresentadas, abríamos a discussão com os participantes sobre as possibilidades de inserção em diferentes cases.

Após serem explicadas as ferramentas, partimos para a "Mão na Massa". A turma foi dividida em três (03) grupos. Cada grupo recebeu uma situação-problema para que pudesse construir um plano de aula com uso do smartphone que contemplasse ao menos uma das ferramentas apresentadas durante a oficina. Para que os participantes pudessem estar imersos na dinâmica, pedimos que considerassem os contextos em que estavam inseridos, além de disponibilizarmos um modelo mais prático e objetivo de plano de aula.

Para tanto, criamos situações-problema, baseados em nossas vivências pedagógicas, sobre o uso do smartphone, quais foram: (i) Estou concluindo um conteúdo relevante e quero avaliar se meus alunos aprenderam. Como vou fazer isso? (ii) Vou iniciar um novo conteúdo e gostaria de fazer um levantamento dos conhecimentos prévios dos meus alunos. Como posso fazer isso? (iii) Os alunos produziram vários trabalhos com imagens, como culminância do projeto gostaria de valorizar esses trabalhos montando uma apresentação em vídeo. Como posso fazer isso? Essas situações foram sorteadas no momento da partilha dos grupos.

Após a construção do plano de aula, cada grupo apresentou seu plano contemplando o uso do smartphone, as ferramentas apresentadas durante a oficina e ainda buscando contextualizar às suas realidades escolares. Logo após foi realizado um quiz no Kahoot ${ }^{5}$ com perguntas sobre o que foi ministrado.

Elaboramos um questionário de avaliação da formação, no qual também recolhemos algumas informações sobre o perfil dos participantes, tais como: se leciona em escola pública e/ou privada, qual a área de formação, qual a percepção sobre o uso do smartphone na sala de aula, a faixa etária, assim como questões acerca do procedimentos adotados durante a oficina. Esses dados serão discorridos na próxima seção.

\section{Resultados e Discussões}

Com a provocação inicial usando o MentiMeter, observamos que os participantes da oficina percebem os smartphones como uma forma de inovação no ensino, assim como uma forma de promover a interação na sala de aula, sendo as palavras em destaque na nuvem de palavras formada, como mostra a Figura 1. Outras palavras aparecem em destaque, tais como alcance, avanço, ampliar o conhecimento, suporte, ou seja, os participantes enxergam o smartphone do ponto de vista de uma ferramenta que poderá auxiliar no ensino do professor e na aprendizagem do aluno.

\footnotetext{
${ }^{2}$ Disponível em: <gg.gg>. Acesso em: 29 set. 2019.

${ }^{3}$ Disponível em: <plickers.com>. Acesso em: 29 set. 2019

${ }^{4}$ Disponível em: <photos.google.com>. Acesso em: 29 set. 2019

${ }^{5}$ Disponível em: <kahoot.com>. Acesso em: 29 set. 2019
} 
VIII Congresso Brasileiro de Informática na Educação (CBIE 2019)

Anais dos Workshops do VIII Congresso Brasileiro de Informática na Educação (WCBIE 2019)

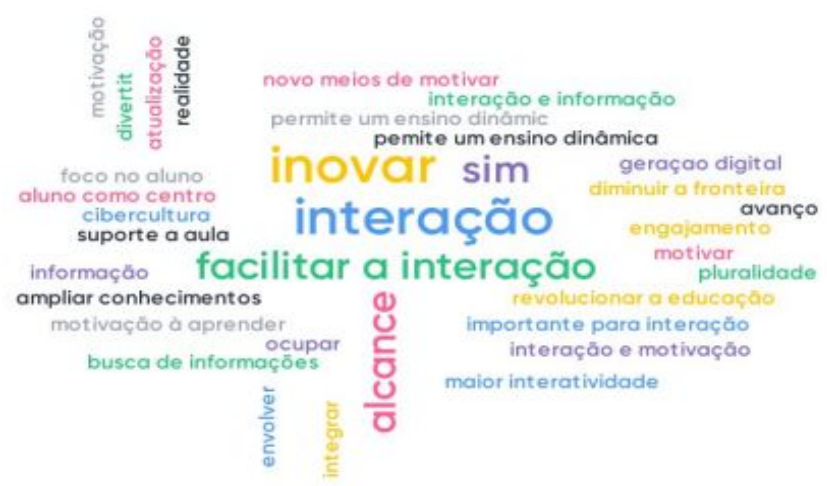

Figura 1. Nuvem de palavras formada a partir da pergunta de provocação inicial: Qual a importância do uso dos smartphones na sala de aula?

Ao prosseguir com a proposta da oficina, conversamos sobre as ferramentas do smartphone e algumas estratégias de como utilizá-lo de maneira mais otimizada em sala de aula, utilizando a metodologia BYOD através de recursos que possuem na maioria dos aparelhos dos alunos, tais como câmera, bloco de notas, agenda. Discutimos sobre a popularização dos dispositivos com sistema operacional Android e pesquisas como a de Melo e Maia (2019) que mostra a abrangência de dispositivos com essas configurações específicas no âmbito da educação básica pública, assim como seu acesso.

Ao abordar os conteúdos, buscamos trazer de nossas práticas exemplos de usos desse aparelho e como melhor se adequaria, mostrando cases de uso com e sem internet. Quando utilizamos a ferramenta Plickers, observamos um ambiente mais perto do professor da escola pública (ver Figura 2). Dos presentes, questionaram sobre esse uso e a falta de internet móvel, o que impossibilitaria de, por exemplo, um trabalho como uma pesquisa simples no navegador da internet se tornaria difícil de ser realizada. Além disso, foram comentadas questões acerca da exclusão dos estudantes que não possuem essa ferramenta e estratégias de como incluí-los.

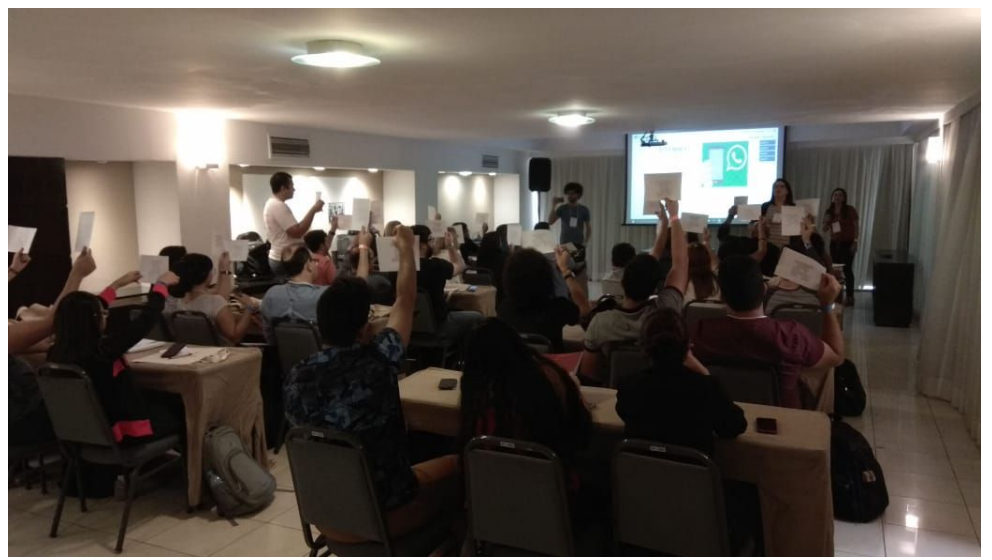

Figura 2. Participantes interagindo com o aplicativo Plickers

Como proposta de dinâmica, dividimos os participantes em três grandes grupos e pedimos para que elaborassem um plano de aula, conforme apresentado no quadro $1 \mathrm{e}$ na figura 2 abaixo. Com o intuito de desfazer a formalidade de um plano de aula, pois poderíamos ter alguém que não fosse da área na formação, elaboramos perguntas sobre a proposta, na qual a resposta seriam os itens de um plano de aula simplificado. Os 
VIII Congresso Brasileiro de Informática na Educação (CBIE 2019)

Anais dos Workshops do VIII Congresso Brasileiro de Informática na Educação (WCBIE 2019)

objetivos, a metodologia, os recursos e a avaliação foram os itens cobrados, que aparecem no cabeçalho do quadro abaixo através das perguntas, respectivamente.

\begin{tabular}{|c|c|c|c|c|}
\hline $\begin{array}{c}\text { Plano } \\
\text { de } \\
\text { Aula }\end{array}$ & $\begin{array}{l}\text { O que eu quero que meus } \\
\text { alunos aprendam? }\end{array}$ & $\begin{array}{l}\text { O que eu vou fazer } \\
\text { para que eles } \\
\text { aprendam? }\end{array}$ & $\begin{array}{c}\text { Qual } \\
\text { ferramenta } \\
\text { eu vou usar? }\end{array}$ & $\begin{array}{l}\text { Como vou saber } \\
\text { se eles } \\
\text { aprenderam? }\end{array}$ \\
\hline PA1 & $\begin{array}{l}\text { Operações básicas de } \\
\text { matemática/Questionário de } \\
\text { conhecimentos básicos } \\
\text { (levantamento de conceitos } \\
\text { prévios). }\end{array}$ & $\begin{array}{l}\text { Verificar assuntos } \\
\text { com menos acertos e } \\
\text { reforçá-los com } \\
\text { estratégias } \\
\text { diversificadas. }\end{array}$ & Metimeter & $\begin{array}{l}\text { Aplicação de novo } \\
\text { questionário após } \\
\text { o reforço dos } \\
\text { assuntos que } \\
\text { constatou-se } \\
\text { defasagem. }\end{array}$ \\
\hline PA2 & Lógica de programação & $\begin{array}{l}\text { Vídeos gravados } \\
\text { sobre a temática e } \\
\text { disponibilizado no } \\
\text { YouTube tendo uma } \\
\text { visualização prévia } \\
\text { dos alunos } \\
\text { consolidando em } \\
\text { sala de aula. }\end{array}$ & Metimeter & $\begin{array}{l}\text { Aplicação de } \\
\text { questões } \\
\text { interativas com a } \\
\text { ferramenta }\end{array}$ \\
\hline PA3 & Figuras Planas & $\begin{array}{l}\text { Utilizar uma } \\
\text { ferramenta de } \\
\text { gamificação para } \\
\text { fixar o conteúdo } \\
\text { ministrado. }\end{array}$ & Kahoot & $\begin{array}{l}\text { Através do } \\
\text { resultado do jogo. }\end{array}$ \\
\hline PA4 & $\begin{array}{l}\text { Aspectos histórico-culturais } \\
\text { associados ao uso de } \\
\text { ferramentas tecnológicas }\end{array}$ & $\begin{array}{l}\text { Formação inicial de } \\
\text { alunos } \\
\text { multiplicadores; } \\
\text { Aula de campo com } \\
\text { produção } \\
\text { audiovisual }\end{array}$ & $\begin{array}{l}\text { Smartphone, } \\
\text { Google Fotos, } \\
\text { Mentimeter e } \\
\text { Plickers (caso } \\
\text { não tenham } \\
\text { acesso à } \\
\text { internet na } \\
\text { hora da } \\
\text { avaliação) }\end{array}$ & $\begin{array}{l}\text { Avaliação vertical } \\
(50 \%) \text { e avaliação } \\
\text { por pares }(50 \%) \\
\text { feita pela } \\
\text { ferramenta } \\
\text { utilizada no } \\
\text { momento }\end{array}$ \\
\hline
\end{tabular}

Com os planos de aula feitos, desafiamos para apresentarem para os colegas e socializamos as discussões sobre cada atividade planejada. Observamos que os participantes tiveram ideias de integrar a ferramenta com atividades integradas, com projeto, e em sua maioria, o dispositivo foi utilizado como algo que auxilie o aluno no processo de aprendizagem.

Além disso, a avaliação se configurou como instrucional, na qual o professor terá como feedback da aprendizagem do aluno a sua taxa de acertos e erros. Para que a mudança de paradigma aconteça, é demandado tempo e esforços para que essas tecnologias sejam efetivamente integradas no processo de ensino [Unesco 2014]. Notamos um grande engajamento dos participantes no momento da discussão do plano e das estratégias que utilizaram para integrar o dispositivo na situação recebida (ver Figura 2). 


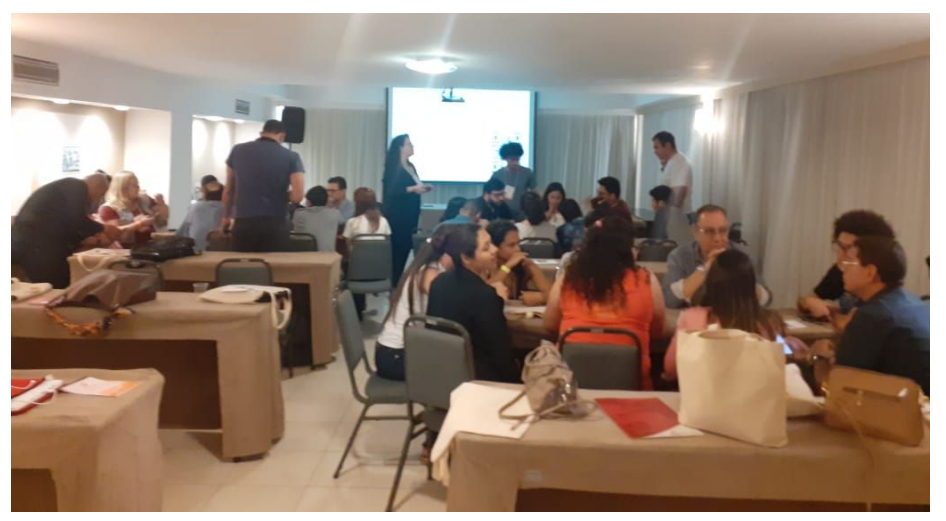

Figura 2. Momento de interação dos participantes ao planejarem as aulas com o uso do smartphone

Os participantes apresentaram seus planos, um de cada vez. Como fechamento, comentamos sobre as propostas e todos os presentes avaliaram como viáveis de serem aplicadas nas propostas de níveis as quais se comprometeram.

Ao final da formação, com o intuito de fechamento de ideias e provocações finais, aplicamos um survey com o aplicativo Kahoot. Ao exibir a ferramenta, constatamos que a grande maioria não a conhecia. Os participantes se engajaram com a atividade gamificada e responderam todas as questões. Na medida em que mostramos o seu uso juntamente com eles, comentamos sobre as possibilidades de aplicação e suas estratégias de integração no processo de ensino.

Ao analisar os dados do instrumento diagnóstico, dos 28 participantes da oficina, verificamos que houve um balanceamento entre os sexos e faixas etárias, tendo desde participantes mais jovens até pessoas com mais de 50 anos. Isso mostra que o público que está interessado na problemática não são apenas os mais idosos, ou os mais novos, muito menos de um sexo específico.

Sobre o nível de formação desses participantes, tivemos como resultados: $64 \%$ da graduação, $18 \%$ com especialização, $14 \%$ com mestrado e $4 \%$ com doutorado. Dos participantes que atuam na educação básica, notamos que apenas um atua no setor privado e os demais, em sua maioria, nos anos iniciais do Ensino Fundamental e no Ensino Médio.

Quando perguntamos quando os participantes já participaram anteriormente de alguma formação sobre o uso pedagógico do smartphone, observamos um cenário preocupante (ver Gráfico 1). Isso mostra que o nosso trabalho teve importância na medida que serviu como provocador desses professores e para conhecimento da ferramenta sobre um viés pedagógico, visto que praticamente $80 \%$ dos participantes nunca tiveram uma formação para esse uso. 
VIII Congresso Brasileiro de Informática na Educação (CBIE 2019)

Anais dos Workshops do VIII Congresso Brasileiro de Informática na Educação (WCBIE 2019)

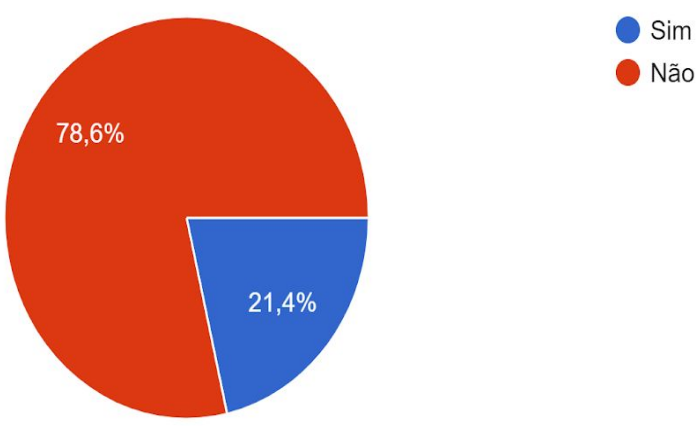

\section{Gráfico 1. Você já participou de alguma formação sobre o uso pedagógico dos smartphones?}

É necessário que iniciativas como essa sejam mais difundidas e que gestão pedagógica juntamente com professores enxerguem a possibilidade que essas ferramentas podem trazer quando integradas de maneira pedagógica e consensual juntamente com os estudantes nas aulas, conforme sugere a Unesco (2014).

Quando perguntamos sobre o nível de interação proporcionado por uma atividade com viés pedagógico com o uso do smartphone, quase $100 \%$ dos participantes reconheceram como níveis extremamente elevados de importância. Uma ferramenta como o smartphones, que têm o interesse dos estudantes e pode ser usada para fins pedagógicos está em evidência.

Ao tratar sobre os pontos positivos para o uso da ferramenta, constatamos que os professores enxergam essa tecnologia como promotora de interação, engajamento dos estudantes na aula e praticidade, reconhecendo sua acessibilidade de uso por parte dos alunos. (ver Gráfico 2).

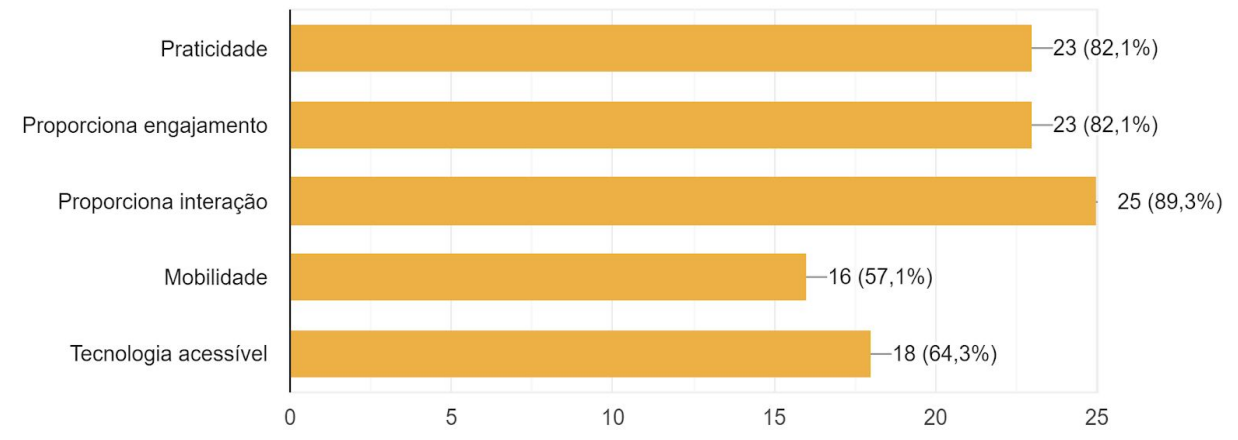

\section{Gráfico 2. Pontos positivos destacados pelos participantes da formação sobre o uso pedagógico dos smartphones}

Ao perguntar sobre os pontos negativos, os professores assinaram que o principal fator para a não utilização desses dispositivos na sala de aula é a falta de WiFi nas escolas, seguido do acesso indevido e desorientado das redes sociais na escola (ver Gráfico 3). 
VIII Congresso Brasileiro de Informática na Educação (CBIE 2019)

Anais dos Workshops do VIII Congresso Brasileiro de Informática na Educação (WCBIE 2019)

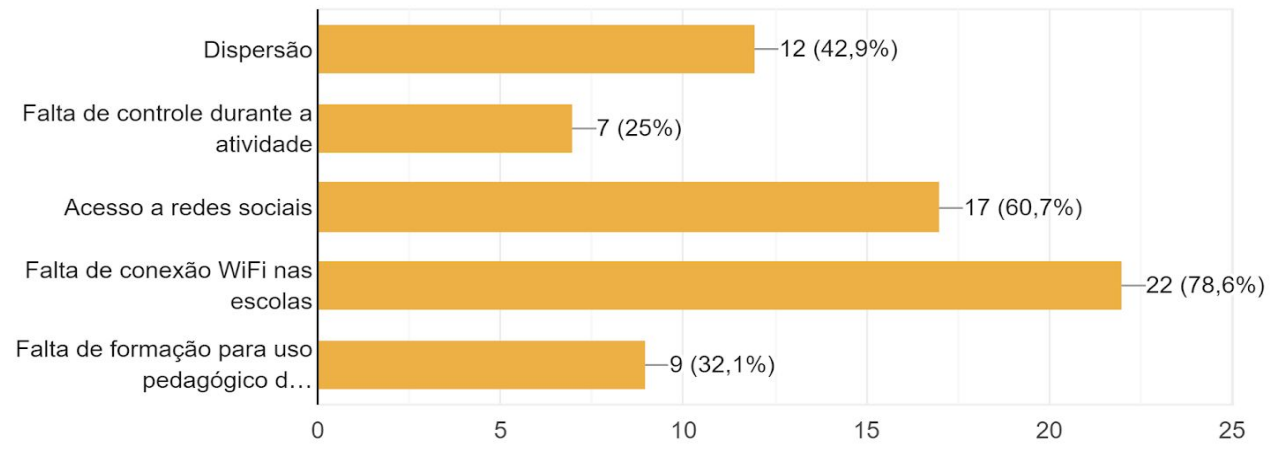

\section{Gráfico 3. Pontos negativos destacados pelos participantes da formação sobre o uso pedagógico dos smartphones}

Ainda sobre os resultados do teste diagnóstico, metade dos participantes já participaram de alguma prática pedagógica com o uso do smartphone. Isso mostra que, apesar de não terem participado de uma formação para o seu uso pedagógico, o smartphone já esteve presente em alguma experiência pedagógica de 50\% dos participantes da formação.

Ao avaliarem o seu nível de engajamento com as atividades da oficina, observamos um alto índice de participação (ver Gráfico 4), o que nos indica que os participantes gostaram de participar dos momentos de discussão, de estudo, de exploração e do momento do planejamento da aula com o dispositivo móvel.

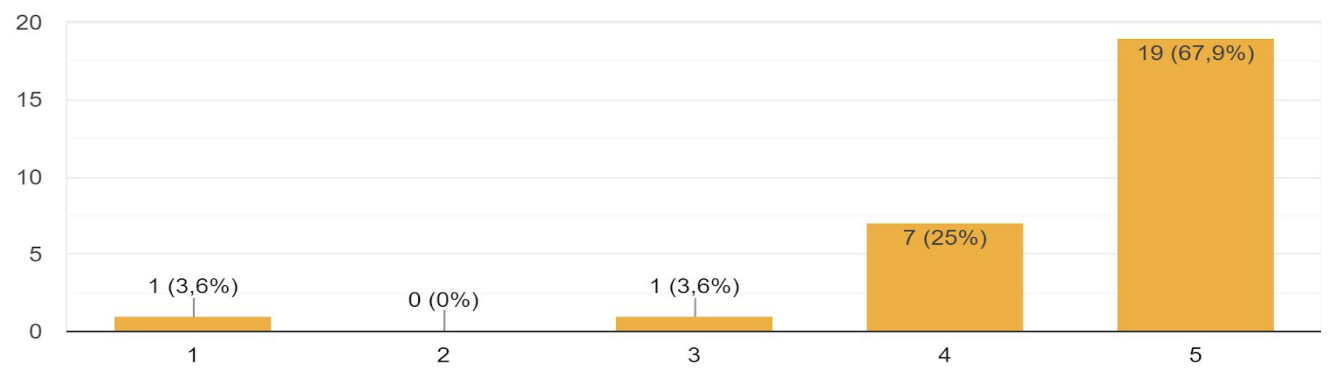

Gráfico 4. Nível de engajamento dos participantes da oficina

A seguir, faremos algumas considerações sobre o que a formação e as observações feitas nos levaram a inferir.

\section{Considerações}

A discussão sobre o uso dos smartphones em sala de aula tem se intensificado. Essa ferramenta possibilita o acesso a internet de forma individualizada e amplie as possibilidades na promoção da aprendizagem, além de ajudar nas atividades diárias que ocorrem em sala de aula como anotações, pesquisas e atividades, o uso desses dispositivos permitem uma participação mais efetiva dos alunos, possibilitam uma aprendizagem de forma assíncrona e oportuniza a colaboração, aumentando a comunicação.

Vale ressaltar que o uso de smartphones precisa ocorrer de forma planejada com objetivos definidos e claros, pois percebemos nos discursos dos professores participantes da oficina ainda uma desconfiança quanto a aplicabilidade do smartphone 
VIII Congresso Brasileiro de Informática na Educação (CBIE 2019)

Anais dos Workshops do VIII Congresso Brasileiro de Informática na Educação (WCBIE 2019)

na sala de aula. Nota-se ainda uma falta de formação quanto ao uso dessa ferramenta e como ela pode ser explorada.

Com essa oficina, esperamos termos contribuído na formação de professores, tornando-os aptos a explorar as tecnologias móveis e utilizar o smartphone na sala de aula, a fim de integrar seus recursos em suas aulas e elaborar práticas inovadoras.

\section{Referências}

Alves, E. D. G.; Vieira, M. F. (2015). Celular e sala de aula: dos limites às possibilidades. In: Anais do XXI Workshop de Informática na Escola (WIE 2015).

Borba, M. de C.; Lacerda, H. D. G. (2015). "Políticas públicas e tecnologias digitais: um celular por aluno”. Educação Matemática Pesquisa (EMP), São Paulo, v.17, n.3, p.490-507.

Campbell, K.; Mehr, H.; Mayer, B. (2013). "Education Technology in India: Designing Ed-Tech for Affordable Private Schools".

Melo, E. M.; Maia, D. L. (2019). O uso dos smartphones por estudantes da pós-graduação: Um estudo de caso. In: Anais do IV Congresso Regional sobre Tecnologias na Educação (Ctrl+E 2019).

Santaella, L. (2013). “Comunicação ubíqua - repercussões na cultura e na educação". São Paulo: Paulus.

Sharples, M., Arnedillo-sánchez, I., Milrad, M.; Vavoula, G. (2009). Mobile learning. Springer Netherlands, p. 233-249.

Silva, A. P.; Silva, S. R. F. (2014). O Uso do Excel no Tratamento da Informação: Relação com os Saberes e as Dificuldades dos Docentes em Formação. In: Anais dos Workshops do IV Congresso Brasileiro de Informática na Educação (CBIE 2015).

Unesco. (2014). "Policy Guidelines for Mobile Learning”. Organização das Nações Unidas para a Educação, a Ciência e a Cultura: 7, place de Fontenoy, 75352. Paris/France, 2014.

West, D. M. (2013). Mobile Learning: Transforming Education, Engaging Students, and Improving Outcomes. In: Brookings Policy Report. 